Адрес статьи / To link this article: $\underline{\text { http://cat.ifmo.ru/ru/2017/v2-i1/95 }}$

\title{
Проблематика гипертекста в философии
}

\author{
М.Ю. Солодов \\ Московский государственный университет имени М.В. Ломоносова, Россия \\ setsovsemne@gmail.com
}

\begin{abstract}
Аннотация. В работе проанализированы известные философские концепции, связанные с созданием, чтением и пониманием текста. Предлагается выделять в качестве ключевых характеристик гипертекста неопределенность структуры, автора и читателя. На основании анализа предлагается пост-неклассическое понимание гипертекста, как предмета научного исследования.
\end{abstract}

Ключевые слова: гипертекст, философия, постмодернизм

\section{1. Введение}

В современном мире технологии всё более глубоко проникают в нашу жизнь и меняют её. В частности, под влиянием такого феномена, как гипертекст, меняются культура и текстовая онтология. Несмотря на то, что сам термин «гипертекст» был предложен ещё в 1965 году [25], в современной науке пока не сложилось ни единого понимания этого явления, ни единого методологического аппарата. Зачастую исследователи прибегают скорее к описанию, нежели к определению гипертекста, обращаясь к таким его свойствам, как нелинейная и многоуровневая структура, мультимедийность, многозначность и т.п. $[9,16,17]$. Это происходит по причине ряда методологических трудностей. Во-первых, при работе с гипертекстом трудно выделить не только предмет исследования, но и сам объект (см. ниже), во-вторых, изучение гипертекста почти всегда становится междисциплинарным, и, в-третьих, при попытках сравнительного анализа классического текста и гипертекста легко столкнуться с тем, что нет четкого разделения этих понятий.

В данной статье обратимся к тем путям решения связанных с применением гипертекстовых структур проблем, которые предлагает современная философская мысль. Ведь для исследователей гипертекстов постепенно становится традиционной отсылка к работам постмодернистов $[5,10-12,16,19]$, что легко объяснить взаимопроникновением постнеклассической науки и культуры [8]. Прежде всего, следует задать структуру статьи. Мы выделяем три критерия демаркации гипертекста и классического текста, каждый из которых основан на неопределенности гипертекста: неопределенность структуры, читателя и автора; рассмотрим каждый из них подробнее.

Неопределенность структуры текста объединяет в себе не только «технологические» свойства гипертекста, такие как нелинейная или сетевая структура и мультимедийность, но и 
более сложные свойства: смысловую, семантическую, лингвистическую и др. многоуровневости текста. К неопределенности структуры гипертекста можно отнести и такую его особенность, как невозможность выделения конкретного текста в текстовом поле. Но границы гипертекста размыты не только в материальном пространстве, но и в пространстве субъектов. Во-первых, весьма сложно выделить автора текста, поскольку ряд технологий поддерживают коллективное письмо, а некоторые авторы пользуются псевдонимами либо иными способами маскируют себя в текстах. Во-вторых, в каждом тексте вольно или невольно заложены отсылки к другим текстам и заимствования из них. И в-третьих, многое в тексте определяется самим читателем, начиная с того, что каждый может вырабатывать свои стратегии чтения и заканчивая тем, что при чтении люди зачастую «вчитывают» определенные значения и смыслы в текст. Отсюда вытекает вывод о неопределенности читателя.

\section{2. Неопределенность структуры}

В работах философов-постмодернистов легко найти примеры анализа структуры текста. Например, Делез и Гваттари в работе «Ризома» рассматривают концепцию текста, в которой они сравнивают его с корневой системой грибницы - сложной сети, каждый элемент которой связан с другими, однако может существовать и независимо. Это единство многообразных, независимых элементов авторы противопоставляют классическим текстам, которые, как они считают имеют структуру, подобную корневой системе дерева. В этой связи представляется интересным, что несмотря на очевидную аналогию с гипертекстом, сами авторы к этому термину не прибегают, они называют ризомой именно текст, который как бы проникает в мир, выходя за собственные границы: «...книга - не образ мира, согласно укоренившемуся верованию. Она создает ризому с миром, имеется параллельная эволюция книги и мира, книга обеспечивает детерриторизацию мира, но мир осуществляет ретерриторизацию книги, которая в свою очередь сама детерриторизуется в мире» [6]. Эта мысль видится нам одной из самых важных, поскольку и книги, и тексты, став электронными, понемногу начали терять свои границы - обычная книга физически ограничена своей обложкой, а книга, оформленная в отдельном файле, хотя имеет понятные границы, но может, тем не менее, содержать ссылки, автоматически приводящие к другим файлам или веб-страницам; наконец, Википедия хотя формально и ограничена теми страницами, которые находятся в её домене, но уже сейчас зачастую содержит ссылки на различные материалы на других ресурсах. Таким образом, в результате двух тенденций: с одной стороны, взаимопроникновения электронного информационного поля и материального мира, а с другой стороны, «электрификации» текста, современный текст сближается с материальным миром, в каком-то смысле формируя новую реальность.

Эта идея не нова. Так, Бахтин, анализируя сосуществование реального мира и миров текстов и значений, подчеркивал, что в пределах подобных рассуждений мир сужается до текста, а текст расширяется до мира. Авторы, читатели и тексты как бы ведут диалоги друг с другом, формируя тем самым особую реальность. Наиболее отчетливо это можно увидеть на примере гуманитарного научного познания: специалисты часто прибегают к трактовкам и анализу различных текстов, которые могут являться как объектом исследования, так и его теоретикометодологическим основанием [3].

Лотман, исследуя тексты с культурологической и лингвистической точек зрения, приходит к выводу, что в любом тексте можно выделить два особых уровня: уровень кода и уровень смысла. В данном случае Ю.М. Лотман, описывая код как особый инструментарий, обусловленный культурой и обществом, отказывается от присущей лингвистике традиции разделения значений и смысла, поскольку автор текста может использовать для передачи смысла не только уровень смысла, но и сам код [13]. Это иллюстрируется примерами из художественной литературы: в ней речь используется не только как носитель смысла и значения, но и как инструмент, позволяющий за счет определенного звуко-интонационного ряда как дополнять «атмосферу» произведения, так и наполнять её не выраженными прямо в словах смыслами. Именно феномены понимания и смысла легли в основу философских концепций, анализирующих текст (часто ещё не электронный) как многоуровневую структуру с неопределенными границами.

Умберто Эко представил более сложную концепцию структуры текста. Он предложил выделять десять уровней текста, которые пересекают и дополняют друг друга при чтении.

International Culture \& Technology Studies, Vol. 2, No. 1 
Некоторые из них заданы в тексте потенциально, и их актуализация зависит от читателя, а некоторые находятся за пределами самого текста и "выходят" к культуре: например, это могут быть идеологические структуры, которые отражают видение картины мира автором, социальный контекст написанного и т.д. Можно сказать, что Эко рассматривает текст не только как объект, но и как процесс - процесс его создания и чтения [21, 22].

Похожие идеи можно найти в работах Р. Барта. Например, в «Смерти автора» он пишет: «текст представляет собой не линейную цепочку слов...но многомерное пространство, где сочетаются и спорят друг с другом различные виды письма, ни один из которых не является исходным; текст соткан из цитат, отсылающих к тысячам культурных источников» [1]. В его концепции текст представлен как система, в которой сочетаются несколько уровней (или кодов), на каждом из которых происходит взаимодействие текста с другими текстами, культурой, социальными нормами и пр. [2]. При этом Барт придерживается позиции, что «нельзя войти дважды в один текст», поскольку тот живет своей жизнью - меняет собственную структуру, «строит» новые связи с миром и «разрушает» старые.

Ещё одна концепция представлена в работах Бодрийяра. Речь идет о «гипертекстуальной» пантекстуальности реальности. Вводя конструкт симулякра, Бодрийяр обосновывает позицию, согласно которой в современном мире собственно материальный мир, а также мир, созданный искусственно (с единственной целью - трансляции определенных идей), безвозвратно переплетаются, результатом чего является парадоксальный феномен, не имеющий ни материально, ни идеально обусловленного значения и существующий только для того, чтобы «оправдать свое существование». Мы вновь видим «новый мир», формирующийся под действием двух тенденций: формирования обществом определенной гиперреальности и её смещения с реально существующей реальностью. Мир, где становится нелегко отличить людей, стоящих на автобусной остановке, от людей, нарисованных на рекламном плакате на этой остановке. Здесь хорошо прослеживается идея развития деятельности человека по изменению природы полностью овладев миром природы, изначально независимым от воли людей, общество оказалось в мире, созданном им самим, но вновь независимым от него, и процесс «овладения миром» начинается снова [4].

\section{3. Неопределенность автора}

Текст может быть неопределенным также и с точки зрения автора. Во-первых, бывает весьма сложно строго выделить и отделить друг от друга смысл текста и замысел автора. Данная проблема породила специальное научное направление - герменевтику. Но если герменевтика чаще всего исходит из того, что у автора был какой-то определенный замысел, то некоторые исследователи приходят к выводу о том, что таковой может вовсе не существовать. Например, Эко предложил концепцию закрытых и открытых текстов, в которых автор может задавать неограниченное количество смыслов, при этом ограничивая читателя определенными рамками и правилами их трактовки [22].

Лотман подчеркивал, что даже если мы рассматриваем текст как осознанный акт коммуникации, нацеленный на определенную аудиторию, нельзя забывать о том, что автор сам является частью этой аудитории. Иначе говоря, некоторая доля смысла, заложенная в тексте, предназначена исключительно автору, а другая часть - собственно аудитории. Автор волен сам выбирать соотношение этих посланий в своем произведении. Кроме того, создавая текст на уровнях кода и смысла, автор выбирает между его тематическим наполнением, средствами выражения и сюжетным наполнением, которое представляет собой нарративное отображение неструктурированных во времени идей и смыслов [13].

В творчестве Мишеля Фуко автор текста предстаёт в несколько иной роли. Вместо того, чтобы анализировать автора как личность, исследователь предлагает взглянуть на него как на социально-экономический контекст написанного. В таком понимании текст - это не только результат работы конкретного человека, но и своеобразный продукт времени, и как таковой он несёт в себе следы взаимодействия общества, культуры и социальной реальности. Такими следами являются знаки, язык, идеология и эпизоды исторически значимых событий [20]. 
Бахтин придерживался похожей точки зрения. По его мнению, в тексте можно найти отражения общественного строя, культурной среды и различных социальных отношений, что делает текст универсальным объектом гуманитарного исследования. Текст перестаёт быть проекцией реальности и становится ею самой, автор же становится её инструментом, фиксирующим диалоги, в которые вступают реальность и другие тексты [3].

$\mathrm{C}$ похожей позиции роль автора текста рассматривал и Барт. Он подчеркивал, что не стоит рассматривать автора текста как личность, сформулировавшую свою мысль в письменной форме. Ведь при написании текста через автора говорит мир, в котором он живет: культура, общественные ценности, язык. Слова содержат не только те значения, которые заложены в них автором, но и те, которые в них появляются в результате взаимодействия с другими словами и другими текстами $[1,2]$.

\section{4. Неопределенность читателя}

По другую сторону от автора находится читатель текста. И если рассматривать текст как динамичную изменяющуюся реальность, то нельзя не отметить, что меняется она в том числе и в ходе чтения, а потому необходимо рассмотреть ещё одно фундаментальное свойство гипертекста - неопределенность читателя.

В концепции Эко читателю отводится важное место в онтологии текста. Читатель выбирает свою собственную стратегию чтения и тем самым формирует структуру текста: нарративную последовательность, переплетение смысловых уровней и т.п. Если при этом актуализация заложенных в тексте смыслов зависит от читателя (от того, найдет ли он их, либо привнесёт свои), то текст превращается в продукт совместного творчества автора и читателя [21, 22].

Барт доводит данную идею до крайности: «...рождение читателя приходится оплачивать смертью Автора» [1]. Речь здесь идет, конечно, не о смерти конкретных людей, а об их роли в тексте. Для Барта читатель ценен тем, что благодаря ему каждый текст становится бесконечен. Становятся возможными бесконечное множество трактовок текста, ни одна из которых не может претендовать на рациональность и объективность. Читатель как бы сливается с автором текста, и вместе с тем сливаются чтение и письмо. Для того, чтобы подчеркнуть этот факт, Барт выделял классический текст (текст-чтение) и текст-письмо [2]. Первый принципиально ограничен в трактовках и в известной мере как бы замкнут сам в себе, тогда как второй по своей природе подразумевает множественность и «начинает игру», в которую волей-неволей читателю приходится играть.

Авторы Ризомы тоже отводили читателю не последнюю роль. По их мнению, читатель использует текст как своеобразную карту реальности для того, чтобы «проложить себе маршрут» через реальность и «ориентироваться на местности». За этой операцией стоит не только выбор пути чтения текста, но и определение того, как этот текст впишется в существующую картину мира. Но ведь при этом меняется не только текст, но и окружающий человека мир. Он обогащается прочитанным, начинает «сверкать новыми красками», в нем появляются новые смыслы и значения [6].

Лотман с одной стороны развивает эту идею, подчеркивая, что читатель не свободен при трактовке текста, а ограничен собственным культурным и личным опытом. Например, не каждый может понять сложные научные работы или отсылку к какому-то личному событию в жизни автора. Более того, читатель ограничен и на уровне кода. Простейшим примером являются различия в языках и диалектах, в рамках которых читатель, однако, волен выбирать, каким кодом ему пользоваться. Но вместе с тем отмечается, что «текст стремится уподобить аудиторию себе, навязать ей свою систему кодов, аудитория отвечает ему тем же»; на уровне кода происходит диалог не только о содержании смысла, заключенного в этом коде, но и том, как именно этот код определить и использовать [13].

В работе Дерриды рассматривается проблематика сочетания мышления и письма. Ключевое отличие между этими процессами, которое выделяет автор, заключается в том, что письмо всегда носит нарративный (линейный) характер, в то время как мышление не распределено по времени однозначно. Деррида видит мышление запертым в устном и письменной 
повествовании, что, однако, оставляет пространство как для неоднозначности выражения мыслей в тексте и речи, так и для извлечения из них смысла [7]. С этой точки зрения гипертекст можно представить как инструмент освобождения мышления человека от рамок, в которые оно было заперто привычными способами объективизации.

Однако не все авторы оптимистично настроены на этот счет. В работах Маклюэна, объединённых идеей «средство коммуникации есть сообщение», обосновывается теория, согласно которой общество в целом и каждый человек в отдельности находятся под влиянием господствующих средств коммуникации (будь то книги или мультимедийное пространство) [14, 15]. Но тем не менее влияние это носит весьма разнородный и не всегда предсказуемый характер.

\section{5. Гипертекст и текст}

Мы рассмотрели ряд концепций и выделили три основных неопределенности, свойственных тексту: структуры, автора и читателя. Однако несложно заметить, что выделенные черты на первый взгляд нисколько не помогают определить, чем же гипертекст отличается от классического текста, поскольку все они свойственны отчасти им обоим. Можно далее пойти двумя путями: определять гипертекст узко или широко. При узком рассмотрении (свойственном современной науке) под гипертекстом мы понимаем определенное технологическое устройство текста - наличие в нем ссылок, полимодальной информации, представление, опосредованное электронными устройствами и т.п. Данная трактовка удобна для проведения экспериментов и сравнительного анализа наличия и отсутствия каких-либо элементов гипертекстуальности, но проблема в том, что в таком ключе невозможно исследовать саму «текстовую» суть гипертекста, поскольку в фокус исследования попадает не текст, а по сути различные способы его репрезентации.

При широком рассмотрении можно прийти к выводу, что любой текст является гипертекстом, ведь практически каждому тексту свойственно наличие ссылок, которые связывают его с другими текстами. При чтении каждого текста читатель основывается на собственном опыте и может найти в нем какие-то новые для себя идеи и смыслы. И каждый написанный текст написан людьми, которые находились под влиянием языка и культуры. Не означает ли это, что можно просто отказаться от демаркации текста и гипертекста, признав, что за этими словами стоит одно и то же явление? На наш взгляд, такой подход также непродуктивен, поскольку принимая его, мы не только отказываемся от изучения природы явления, но идем дальше - отказываем ему в существовании.

Для того, чтобы найти выход из сложившейся ситуации, необходимо рассмотреть, как возникают выделенные нами свойства гипертекста. Дело в том, что хотя потенциально в каждом тексте заложена неопределенность структуры, автора и читателя, актуально она реализуется далеко не всегда. Например, когда прохожий читает объявление о том, что улица закрыта на ремонт, его совсем не интересует технический план ремонта, приказ о его начале и т.п. Однако если бы он планировал проехать по этой улице на машине, его бы интересовала дата завершения ремонта, и тем самым текст взаимодействовал бы с образом будущего мира. Нетрудно найти ответ на вопрос, при каких условиях возникают описанные выше свойства гипертекста. Это по сути одно-единственное условие - взаимодействие текста и человека. Без него в тексте не содержится никакой неопределенности, как бы сложно он ни был представлен с технологической точки зрения. Ведь без человека любой текст - это просто застывший объект материального мира и не более того. Только во взаимодействии с человеком текст может «дышать», «жить» и развиваться.

Исходя из вышеизложенного, можно сделать вывод, что с точки зрения объекта исследования гипертекст и текст - это две реальности, сосуществующие и взаимопроникающие друг в друга. С точки зрения же предмета исследования, гипертекст следует определить как систему, в которой взаимодействуют человек и текст.

\section{6. Заключение}

Представленная пост-неклассическая концепция исследования гипертекста, на наш взгляд, является лишь первым шагом в необходимой проработке методологических проблем. Эти проблемы возникают не только в теоретических исследованиях, но и приводят к эмпирическим трудностям, что неоднократно подчеркивалось в литературе $[23,24]$. Мы считаем, что одной из

Культура и технологии, Том 2, № 1 
отраслей науки, которые могут «возглавить» теоретический прогресс в исследованиях гипертекста, является психология. Поэтому именно в ней, как ни в какой другой науке, необходимо создать единые методологические основания для подобных исследований. Ранее мы обосновали необходимость использования для этих целей аппарата культурно-деятельностной программы [18]. В данной работе мы постарались изложить более фундаментальный подход к проблеме, который, на наш взгляд, позволяет навести мосты для междисциплинарных исследований гипертекста, поскольку мы уверены, что в этой проблемной области без них не обойтись. Однако на этом нельзя останавливаться, поскольку по-настоящему проверить плодотворность предложенного теоретико-методологического подхода можно только в экспериментальных исследованиях.

\section{Литература}

[1] Барт Р. Избранные работы: Семиотика. Поэтика / Р. Барт, Москва: Прогресс, 1989.

[2] Барт P. S / Z / P. Барт, 2001. 232 c.

[3] Бахтин М.М. Эстетика словесного творчества / М.М. Бахтин, М.: Искусство, 1979. 424 с.

[4] Бодрийяр Ж. Симулякры и симуляция / Ж. Бодрийяр, Москва: Постум, 2015. 240 с.

[5] Борсяков Ю.И., Коровин С.В. Философский анализ гипертекста в системе социально-гуманитарных наук // Соврем. пробл. гуманит. и обществ. наук. 2014. № 3. С. 36-45.

[6] Делез Ж., Гваттари Ф. Ризома Минск:, 1996. 7-31 с.

[7] Деррида Ж. О грамматологии / Ж. Деррида, Москва: Издательство «Ad marginem», 2000. 514 с.

[8] Додонова В.И. Проблема корреляции постмодернистской и постклассической рациональностей в современном философском дискурсе / В.И. Додонова, 2011. 1-5 с.

[9] Купер И. Гипертекст как способ коммуникации // Социологический журнал. 2000. № 1. С. 37-59.

[10]Лапошина Д.А. Электронный текст сквозь призму концепции ризомы Ж. Делеза и Ф. Гваттари // Современные проблемы науки и образования. 2014. № 3.

[11]Лапошина Д.А. От линейного текста к гипертексту: отражение в работах Ж. Деррида // Гуманитарные, социально-экономически и общественные науки. 2014. № 11.

[12]Лапошина Д.А. Электронный гипертекст и «диалогизм» М. Бахтина: точки соприкосновения // Исторические, философские, политические и юридические науки, культурология и искусствоведение. Вопросы теории и практики. 2015. № 52 (2). С. 119-121.

[13]Лотман Ю.М. Семиосфера. Культура и взрыв. Вынутримыслящих миров. Статьи. Исследования. Заметки / Ю.М. Лотман, СПб.: Искусство-СПБ, 2000. 704 с.

[14] Маклюэн М. Галактика гутенберга / М. Маклюэн, Киев: Ника-Центр, 2004.

[15]Маклюэн М., Фиоре К. Война и мир в глобальной деревне / М. Маклюэн, К. Фиоре, Москва: Астрель, 2012. $219 \mathrm{c}$.

[16]Саяпин В.О. Вестник пермского университета. Философия. Психология. Социология 2012. № 11 (3).

[17]Соболева О.В. Понятие и оснонвы ехарактеристики гипертекста // Альманах современной науки и образования. 2011. № 55 (12). С. 163-164.

[18]Солодов М.Ю. Гипертекст как предмет психологического исследования в культурно-деятельностной программе // Международный электронный журнал «Образовательные технологии и общество». 2016. № 2 (19). С. 621-629.

[19]Тренева М.Г. Философское обоснование гипертекста // Magister Dixit. 2011. (3). С. 71-75.

[20]Фуко М. Воля к истине: по ту сторону знания власти и сексуальности. Работы разных лет / М. Фуко, Москва: Касталь, 1996.

[21]Эко У. От Интернета к Гутенбергу : текст и гипертекст 1998.

[22]Эко У. Роль читателя. Исследования по семиотике текста. / У. Эко, СПб.: «Симпозиум», 2007. 502 с.

[23]DeStefano D., LeFevre J.A. Cognitive load in hypertext reading: A review // Computers in Human Behavior. 2007. № 3 (23). C. 1616-1641.

[24]Foltz P.W. Comprehension, coherence and strategies in hypertext and linear text // Hypertext and cognition. 1996. C. 109-136.

[25]Wardrip-Fruin N. What Hypertext Is // Proceedings of Hypertext 2004, 15th ACM Conference on Hypertext and Hypermedia. 2004. C. 126-127. 


\title{
The hypertext issues in philosophy
}

\author{
M.Yu. Solodov
}

Lomonosov Moscow State University, Russia

\begin{abstract}
Analysis of the main philosophical concepts devoted to creating, reading and understanding texts has been done. Ambiguities of structure, author, and reader are underlined as the most fundamental features of hypertexts. Based on this analysis a post-neoclassic definition of hypertext is suggested.
\end{abstract}

Keywords: hypertext; philosophy; postmodern

\section{References}

[1] Bart R. Izbrannye raboty: Semiotika. Pojetika / R. Bart, Moskva: Progress, 1989.

[2] Bart R. S / Z / R. Bart, 2001. 232 c.

[3] Bahtin M.M. Jestetika slovesnogo tvorchestva / M.M. Bahtin, M.: Iskusstvo, 1979. 424 c.

[4] Bodrijjar Zh. Simuljakry i simuljacija / Zh. Bodrijjar, Moskva: Postum, 2015. 240 c.

[5] Borsjakov Ju.I., Korovin S.V. Filosofskij analiz giperteksta v sisteme social'no-gumanitarnyh nauk // Sovrem. probl. gumanit. i obshhestv. nauk. 2014. № 3. C. 36-45.

[6] Delez Zh., Gvattari F. Rizoma Minsk:, 1996. 7-31 s.

[7] Derrida Zh. O grammatologii / Zh. Derrida, Moskva: Izdatel'stvo «Ad marginem», 2000. 514 c.

[8] Dodonova V.I. Problema korreljacii postmodernistskoj i postklassicheskoj racional'nostej v sovremennom filosofskom diskurse / V.I. Dodonova, 2011. 1-5 c.

[9] Kupper I. Gipertekst kak sposob kommunikacii // Sociologicheskij zhurnal. 2000. № 1. C. 37-59.

[10] Laposhina D.A. Jelektronnyj tekst skvoz' prizmu koncepcii rizomy Zh. Deleza i F. Gvattari // Sovremennye problemy nauki i obrazovanija. 2014. № 3.

[11] Laposhina D.A. Ot linejnogo teksta k gipertekstu: otrazhenie v rabotah Zh. Derrida // Gumanitarnye, social'nojekonomicheski i obshhestvennye nauki. 2014. № 11.

[12] Laposhina D.A. Jelektronnyj gipertekst i «dialogizm» M. Bahtina: tochki soprikosnovenija // Istoricheskie, filosofskie, politicheskie i juridicheskie nauki, kul'turologija i iskusstvovedenie. Voprosy teorii i praktiki. 2015. № 52 (2). C. 119-121.

[13] Lotman Ju.M. Semiosfera. Kul'tura i vzryv. Vynutrimysljashhih mirov. Stat'i. Issledovanija. Zametki / Ju.M. Lotman, SPb.: Iskusstvo-SPB, 2000. $704 \mathrm{c}$.

[14] Makljujen M. Galaktika gutenberga / M. Makljujen, Kiev: Nika-Centr, 2004.

[15] Makljujen M., Fiore K. Vojna i mir v global'noj derevne / M. Makljujen, K. Fiore, Moskva: Astrel', 2012.219 c.

[16] Sajapin V.O. Vestnik permskogo universiteta. Filosofija. Psihologija. Sociologija 2012. № 11 (3).

[17] Soboleva O.V. Ponjatie i osnonvy eharakteristiki giperteksta // Al'manah sovremennoj nauki i obrazovanija. 2011. № 55 (12). C. 163-164.

[18] Solodov M.Ju. Gipertekst kak predmet psihologicheskogo issledovanija v kul'turno - dejatel'nostnoj programme // Mezhdunarodnyj jelektronnyj zhurnal «Obrazovatel'nye tehnologii i obshhestvo». 2016. № 2 (19). C. 621629.

[19] Treneva M.G. Filosofskoe obosnovanie giperteksta // Magister Dixit. 2011. (3). C. 71-75.

[20]20. Fuko M. Volja k istine: po tu storonu znanija vlasti i seksual'nosti. Raboty raznyh let / M. Fuko, Moskva: Kastal', 1996.

[21] Jeko U. Ot Interneta k Gutenbergu : tekst i gipertekst 1998.

[22] Jeko U. Rol' chitatelja. Issledovanija po semiotike teksta. / U. Jeko, SPb.: «Simpozium», 2007. 502 c.

[23] DeStefano D., LeFevre J.A. Cognitive load in hypertext reading: A review // Computers in Human Behavior. 2007. № 3 (23). C. 1616-1641.

[24]Foltz P.W. Comprehension, coherence and strategies in hypertext and linear text // Hypertext and cognition. 1996. C. 109-136.

[25] Wardrip-Fruin N. What Hypertext Is // Proceedings of Hypertext 2004, 15th ACM Conference on Hypertext and Hypermedia. 2004. C. 126-127. 